\title{
Community Photographs
}

\author{
JANNE SEPPÄNEN
}

\begin{abstract}
The research subject of this article is formed by a project with the title Two Pictures of My Town. The project was carried out during spring 2002 in the town of Tampere, Finland, when town district or suburb communities, and in one case a sixth-form class, were asked to 'get to the bare essentials' of their town district and present them in two photographs with short captions.

The following research questions were asked:

What kinds of visual orders can be found in the paired photographs? What kind of politics of representation is included in these orders? What kind of identity work is expressed by the photographs' visual orders and politics of representation? The photographs were interpreted through a theoretical researcher reading.

Photographs in which the local identity was constructed on the basis of familiar and safe visual orders offered a relatively solid and legitimate basis for local identities. These photographs repeated the visual orders of traditional tourist photographs and nature photography. If the two photographs commented the changes in the look of the neighbourhood, for example the differences between old and new architecture, they offered a more discontinuous basis for local identity construction. On the other hand, they provided alternative surface of identification for those who do not accept prevailing visual orders of the neighbourhood.
\end{abstract}

Keywords: identity, local identity, photography, representation, politics of representation, visual order.

\section{Introduction}

The turn of the $20^{\text {th }}$ century was crucial for photography in that it became a leisure time activity. Kodak's famous slogan 'You press the button, we do the rest' manifested the fact that taking photographs had been developed into a mass product that could be sold. Photography became a possible hobby for everybody, since it was no longer necessary to master the operations of the darkroom or the finest details of exposure.

People began to document the important rituals of their lives, such as birthdays, weddings and funerals, themselves. The photographs took their place as a part of building family identities (see Holland, 1997: 105-109; Wells, 1997: 127-128). The ease of photography, especially, offers people the opportunity to also present their private so-

Janne Seppänen, Professor, Ph.D., Journalism Research and Development Centre, Department of Journalism and Mass Communication, FIN-33014 University of Tampere, janne.seppanen@uta.fi 
cial milieu and its central subjects. Written expression may be more difficult for many, but the threshold for taking photographs is not necessarily as high, of which the popularity of photography as a hobby stands for proof.

Consequently, photography is not merely taking pictures, but also building identity and social interaction. This fact was recognized in the fields of social and media research by the 1960s, when Pierre Bourdieu (et al.) published his well-known research Un art moyen: Essai sur les usages de la photographie (1965). Prior to Bourdieu's book, Roland Barthes had already published his significant articles on the photograph (Barthes, 1987 a \& b). Bourdieu and his research colleagues analysed different kinds of practices in photography, concluding that amateur photography, often regarded as an area of free expression, is actually regulated by several rules related to culture and social class. Moreover, Bourdieu's Durkheimian view points to the ways in which photography both expresses and enforces a family's collective identity (cf. Bourdieu et al., 1990).

Since the 1960s, researchers of communication have explored the relation of photographic representation and cultural identity from several perspectives; the relationship has been discussed with regard to family photography, gender, and ethnic otherness (Hall, 1992a \& b; Hall, 1997a; Slater, 1995; Spence, 1995). During the past decade questions concerning the cultural significance of the photograph have blended with the larger-scale agenda of visual culture research.

The present article also focuses on the photograph and cultural identity. I analyse photographs of residential areas taken by the residents themselves. The research subject is formed by a project with the title Two Pictures of My Town (in Finnish Kaksi kuvaa kaupungistani). The project was carried out during spring/summer 2002 in the town of Tampere, Finland, when town district or suburb communities, and in one case a sixth-form class, were asked to 'get to the bare essentials' of their town district and present them in two photographs with short captions. A specific application for the photographic pairs was designed in the Internet, and the pictures can be viewed at $<$ http://mansetori.uta.fi/kaksikuvaa/ $>$. What is more, the pairs of photographs were also transmitted to applications operating in mobile data terminal equipment, which were tested by a group of people attending an international conference in Tampere in June 2002. Each town district forms a basis for a short story comprising two photographs and their captions - i.e., altogether sixteen pictures portraying eight different town districts.

This article condenses the relations of pictorial expression and cultural identity into the following three research problems.

What kinds of visual orders can be found in the pairs of photographs? 'Visual order' refers presently to regularities concerning the meanings of the visual representations.

What kind of politics of representation is included in these orders? 'Representation' is here viewed constructively, i.e. not as reflecting reality or the intentions of its producer, but as building reality. 'Politics' refers to the actions, i.e. the choices and emphases, exercised when producing a representation.

What kinds of identity formation processes can be detected in the visual orders and the politics of representation applied in the photographs?

\section{In Search of Visual Orders}

Communication research has focused on both everyday life photographs (e.g., family photographs, press photos, advertisements) as well as alternative practices in picture production. 'Alternative' in most cases refers to challenging, in one way or the other, the prevailing ways of representation. As early as the 1970 s, the British Isles saw the 
emergence of the community photography movements, formed by people taking an active stand on portraying their residential areas. The background for these movements was created by residents being concerned about their own living environments, and therefore attempting to make decision-makers aware of their living conditions by setting up exhibitions, printing posters and publishing books (cf. Braden, 1983).

As another example, the workshops of Jo Spence and Rosy Martin can be mentioned; in these workshops the researchers examined their own identities by rebuilding their family albums. Spence and Martin based their work on feminist and psychoanalytic theoretical impulses (Spence, 1995).

A third example is available in the community video production (see Burnett, 1995: 242-251), which emerged as a result of marginal communities (e.g., homosexuals) growing tired of stereotypes of themselves formed in the mainstream publicity, and therefore beginning to produce their own imagery in the wake of low-price video cameras becoming easily available.

All of the above-mentioned fields of alternative pictorial production share the question of representation, which in turn comprises several subquestions: how are the pictures constructed and in what kind of publicity; who controls the equipment of representation; are the people in the pictures merely a passive target or do they form a community that actively constructs its identity? What about the ways in which power is constituted in the pictures as well as in the action of photography? Such questions, among other aspects, have placed pictures and the visual culture in general as conceptions of cultural studies.

Prior to a closer inspection of the Two Pictures of My Town photographs, four concepts essential to the present discussion need to be explored: representation, politics of representation, visual order, and identity.

Stuart Hall (1997b: 24-26) approaches the topic of representation from three different angles. First, a representation can be viewed as a reflection of reality, in which case the essential question is in what ways the representation corresponds to reality. Second, a representation can be regarded as intentional; in other words it can be subjected to the question of what the 'author' of the message wants to convey with this particular representation. Both of these ways of understanding a representation are important with regard to the Two Pictures of My Town project; viewed from the first angle, one may well inquire as to the ways in which the pairs of photographs correspond to the reality of the respective areas. Do the portraits do justice to the areas? Furthermore, the original intentions of the photographers can also be questioned, thus applying the second angle: what do they want to express by these pictures? However, Hall's third way of understanding a representation is the most essential in terms of the present discussion. Thus, the representations will viewed neither as pictures of reality nor as expressions of their authors' intentions, but as constructions, i.e. representations that construct reality. From this point of view representations cannot simply be tested against [the background of] reality, since 'the real' in itself is constituted through representations.

By politics of representation, Hall (1997b: 8) means questioning the prevailing representations. However, thus defined the concept is problematic, because it gives the impression that merely those representations that criticise the current public imagery are political in nature. The present article is based on the idea that all representations are political because they construct the world in a particular way, thereby inevitably excluding other options. Thus, politics of representation means a plan of action that elects certain ways of representation in favour of others not applied. What kind of a shot is selected for representing a demonstration in connection to a piece of news printed in a newspaper? Is it a demonstrator assaulting a police officer or vice versa? 
The aforementioned matters are connected to 'visual order' (see Seppänen, 2001b: 2987). Different kinds of imageries are created into publicity or into private family albums, and these imageries are not arbitrary by nature. Their visual orders or regularities may be, for example, on the one hand formed of what can be seen, and on the other hand of what will not be shown. Newspaper photographs do not illustrate homosexuals kissing, family albums do not present snapshots of domestic violence, and television children's programmes do not feature pornography. Essential in this entanglement of visibility and invisibility is the role of power and knowledge. Michel Foucault's (cf. e.g., 1986) wellknown conception of power entails a strong productive essence, leaving restrictions and restraints as less of essence in terms of power. Seen from this angle, the visible and the invisible taking shape in visual orders signify power in function, and thus certain features of visible reality, as well as the values and norms connected to these features, are strengthened. The power is constituted in the process that produces visibility and thus visual orders. Visibility is also something to strive after, as any politician knows particularly prior to an election. Am I visible, do I belong to the prevailing visual order?

The fourth term, i.e. identity, must be one of the most frequently discussed concepts of cultural studies, albeit also one of the least definite. The present article in many cases applies the term with the epithet 'cultural', which refers to the fact that identities are formed as a result of culture and humane interaction. Thus defined, identity is not merely a psychical concept, but broadens into cultural interaction. As Stuart Hall (1992b: 287) puts it: "Thus, rather than speaking of identity as a finished thing, we should speak of identification, and see it as an on-going process. Identity arises, not so much from the fullness of identity which is already inside us as individuals, but from a lack of wholeness which is 'filled' from outside us, by the ways we imagine ourselves to be seen by others."

It is interesting that Hall defines identifications in terms of their being perceived by the sense of sight; it therefore follows that identities are to a significant extent formed through visual interaction - a thought which has for some time formed the core of psychoanalytical subject concepts (cf., e.g., Lacan, 1977; Silverman, 1996: 126-193). Therefore, we can use visual representations as building blocks for our identities by identifying ourselves with them and presenting them to be viewed by others. The most simple example could be a T-shirt with a picture of a rock star. By wearing the shirt, its carrier works his/her identity, either consciously or unconsciously, through identifying $\mathrm{him} /$ herself to the meanings signified by the picture and communicating via the picture in situations of social interaction.

In conclusion, representations equal constructions and reality itself. Their production, including the choices made during production, equal politics of representation, i.e. a plan of action that generates representations of a particular desired type. Moreover, visual orders in pictures can be defined as crystallised meaningful structures, in which, among other things, the borderline between the visible and the invisible is drawn. Furthermore, identities are built as chains of identification, in which visual orders crystallised in representations play an important part.

\section{The Research Material and Method}

The actual research material consists of pictures and their captions introduced to the Internet, i.e., altogether eight pairs of pictures portraying eight different town districts. On occasion I will also refer to the recorded interviews of those involved with the production of the pictures; however, the interviews cannot be regarded as actual secondary research material. 
Two Pictures of My Town is a part of Evolution of eCommunities project (EeC), which is carried out at the University of Tampere, Journalism Research and Development Centre. Goals of the project include making the use of communications networks more easily available to the citizens and simultaneously building a multidisciplinary laboratory in order to conduct research on networking processes. In practice, the activities and research carried out by the $\mathrm{EeC}$ are concentrated on developing and maintaining Manse Square, a network community operated by the university and the town of Tampere in cooperation with local communities, which include, for example, resident communities of various town districts. The $\mathrm{EeC}$ operates on an action research basis; i.e., the researchers continue to produce web sites for town districts in cooperation with the citizens, simultaneously analysing the issues arising from the action (cf. Heinonen et al., 2000). Local operators are given assistance in constructing channels into webmediated publicity through instruction in the use of the Internet and the production of web-site contents. Thus, the research has gained a functioning connection to practice, which was previously lacking, while local actors are provided with access to the (web) resources offered by the academic world.

The town districts taking part in Manse Square on the Internet have introduced many kinds of imageries on their web sites, and the members of these communities have had the chance to study photography and digital image processing. However, the Two Pictures of My Town project provided the inhabitants a new pictorial forum and the opportunity to ponder upon condensing their own town district into just two pictures. In addition, the project built a basis for research on the dynamics between pictorial expression and local identity. Although the web sites of Manse Square are abundant in pictures, they had not been analysed prior to the Two Pictures of My Town project.

The project was started in February 2000 by sending an e-mail to contact persons of various town districts and the Arts teacher of the Hervanta sixth-form college. The message contained a description of the purpose of the project, including clarification of the fact that the pictures would be presented on the Net and thus also become available for an international public. The pairs of pictures and their captions would be mediated to a NaviTam application operating in mobile data terminal equipment, and the application would be produced by Media Tampere Ltd. for the participants of IAEC conference, which was to take place in the summer of 2002. Thirty of the participants would be given a Nokia communicator (9210i), which runs the NaviTam application. The material itself was built in various ways; in some town districts, one person took the photographs; in others, a group of local inhabitants discussed which pictures would be used; on some occasions, the pictures were 'found' among photographs that had already been brought to public display via the Internet. In most cases, editing the pictures fell on the shoulders of the town district's contact person. The Arts teacher of the Hervanta sixth-form college arranged a contest to select suitable photographs: the pupils worked in pairs and the pictures were judged together. As a whole, people were given as little advice as possible on producing the pictures, so as not to discourage the preferences of each individual community.

However, the present article is not focused on the production of the pairs of pictures or their reception, although production must be discussed to some extent. Instead, the analysis focuses on the web-mediated pairs of photographs with their captions, and the research method is provided by the researcher interpretation (on the problems of researcher interpretation, see Seppänen 2001a). This method entails that the researcher interpret the representations in the light of his/her own practical and theoretical knowledge, thus reading meanings into the representations. The produced meanings do not 
necessarily have much to do with the purposes of the producers of the photographs. Therefore, this article is not particularly 'target-sensitive', but instead via a theoretical interpretation attempts to broaden the field of meanings present in the data.

\section{Tales from the Town in Two Pictures}

Most (14) of the pictures portray different kinds of landscapes, and two are focused on people. The large number of landscape portraits gives a reason for analysing the imagery with a particular focus on visual orders of presenting landscapes. Three landscapes were chosen among the research material with the purpose of selecting as varied sceneries as possible; thus, a nature landscape (Hervanta), a countryside scenery (Teisko) and a landscape of the town (Järvensivu) were opted for. The categorisation should not be understood as being absolute, since it is quite possible for a nature landscape to simultaneously fall into the category of countryside scenery, and a landscape of the town may well resemble countryside scenery. However, the categorisation attempts to depict the relevant dimensions of the whole material.

According to semiotican Eero Tarasti (1990), both presenting and even experiencing the landscape are in essence always culturally defined. A 'pure' scenery, i.e. one free of meanings, does not exist and, moreover, definitions of the landscape are necessarily historical and connected to a certain time and a place. The landscape is constructed differently by, on the one hand, a person who has lived in a city all his/her life and, on the other hand, an inhabitant of northern Lapland living surrounded by 'fjelds' or hills.

Following Tarasti's pattern of thought, the landscape can be either 'outer' or 'inner' for a community; for example, for farmers the countryside landscape is 'inner', as it is essentially connected to their everyday life. Similarly, the same landscape is 'outer' for a city community, as it exists outside the city's immediate habitat. Both cases allow both positive and negative values to be attached to the landscape; for example, for the citydweller the countryside landscape is often idyllic, or, as perceived from the opposite point of view, it may symbolise monotonous hillbilly boredom. For those residing in the countryside, the town landscape may equally represent values either worth pursuing or supposedly threatening to their own lifestyle.

Tarasti applies the concept 'ideal landscape' for referring to those positive values that form the basis for any particular conception of a landscape. Different communities can cherish different kinds of ideal landscapes. Those defending the old architecture of a town will probably hold a different view of ideal landscape than those in pursuit of as financially efficient as possible utilisation of vacant building sites. Rendered in the language of the present research, 'the ideal landscape' means a kind of desirable visual order concerned with landscape; in other words, the main issue is the way the landscape is wanted to be seen. For example, the concept of a Finnish 'national landscape' is attached to a number of assumptions: it is often regarded as worth protecting; moreover, it is seen as a part of the nation's history and the Finnish 'mental landscape'.

One more basis for analysing representations of landscape is to divide them into cultural landscapes and nature landscapes. The visual order of the former includes artefacts made by man (i.e., by culture); for example, roads, buildings and fields. The visual order of the latter attempts to be built of a clean and untouched nature, free from traces of human culture. 


\section{Hervanta: Coexistence of Man and Nature}

A photograph contest was arranged in a sixth-form college in the town district of Hervanta by the school's Arts course teacher and a class of pupils. The purpose of the Two Pictures of My Town project was explained to the pupils and, working in pairs, they received disposable cameras for portraying Hervanta in photographs. The pupils selected the winner among the pairs of pictures they had produced. Although analysing the production process does not lie in the focus of the present article, it is worth pointing out that all the pupils did not reside in the town district of Hervanta, and the producers of the pair of pictures that won the contest were these non-residents. In their discussions with the photography project leader, this pair of pupils hinted at not much liking Hervanta. Therefore, applying Tarasti's (1990) concepts, it can be said that these pupils expressed possibly a less 'inner' relationship to the district of Hervanta than those residing in the area.

The pair of photographs portraying Hervanta build a relation between two elements, i.e., nature and culture. The whole idea of the pair of pictures leans against the meanings connected with nature and culture, the theme of the pair being 'awakening nature'. The first photograph depicts a babbling brook running in the midst of woods, accompanied by the caption "Summer is_approaching - nature awakes". This picture introduces the visual order of the traditional nature and wildlife photograph, typical of which is the non-existence of human traces. Clicking into the second picture, the viewer is faced with the sight of a slightly banal bench that appears to be situated alongside to a jogging track in the woods. The picture has the following caption: "We can live our lives together with nature and enjoy its peacefulness." The interaction of man and nature condenses between the pair of pictures that portray culture penetrating into nature in the form of a jogging track. The bench offers the chance to stop to enjoy "the peacefulness" offered by nature.

These two pictures and captions describing Hervanta are linked to the larger-scale visual order of nature and wildlife photographs, which in turn form 'a second nature' via the media. 'The second nature' refers to the fact that nature is no longer merely a physical entity that exists in a concrete form, but is first and foremost an imaginary area that has in various ways gained the ground that previously belonged to 'real' nature. One of the central ways of experiencing nature is to consume it on the imaginary level; in other words, when selling products in the name of nature, it is important to attach to them an image of doing as little harm to nature as possible. Thus, the representations of the products (i.e., advertisements and other visual orders surrounding the products) are designed in forms that do not create a conflict between nature and culture (i.e., production). For example, advertisements and TV commercials presenting cars often place the product in a setting of nature; in other words, the car is displayed as a natural part of nature (cf. also Toiskallio, 1997: 79). In most cases, advertisements depict nature alongside with culture without any significant conflicts. The imaginary nature also gives promises of the use value of the product by claiming that the product coexists in harmony with nature. Another possible way of building imaginary nature is to present nature without any explicit connections to man-made culture or society. For example, the current mainstream of nature and wildlife photography produces nature by focusing on the beautiful details or spectacles of nature. Pictures of this kind portray nature as pure and clean, untouched and often also exotic. The television nature documentaries concentrating on the wonders of nature are a good example of this type of nature portrayal.

Both ways of building imaginary nature (as described above) can be traced when analysing the two photographs of Hervanta. The first picture shows a clear nature land- 
scape without any additional objects. The second picture, however, depicts a bench that creates an impression of a 'culturalised' nature. The two pictures are similar in that they do not create a conflict between nature and culture.

It is worth noting that the two pictures do not actually relate to Hervanta in any specific way; in other words, the bench alongside the jogging track or the brook running amidst a wintry scenery could be situated almost anywhere. However, in the context of the Two Pictures of My Town project they are connected with Hervanta, therefore in a way suggesting that it is possible to live in peace with nature in Hervanta - not claiming that Hervanta in particular would be ideal for this, however. Nevertheless, the suburb is shown as a nice place particularly because it is close to nature or, figuratively speaking, 'in the midst of woods'.

However, further ironical meanings can naturally be read into the pair of pictures: the banal bench in the middle of nature and the highlighted clichés of nature, i.e. the murmuring brook as an index of awakening nature. These kinds of interpretations of supposed irony bring forth a special meaning for the pictures when viewed from the point of view of cultural identity; I will discuss this viewpoint further in the final conclusions.

Interpreting the Hervanta pictures as abstract representations of nature allows one further point of view, namely that discussed by Jean Baudrillard (1988). According him (Baudrillard 1988: 170), there are four ways to perceive the relationship between picture and reality: first, the picture can be described as a reflection of reality; second, it may cover and distort the reality; third, it can cover the absence of reality; and fourth, it can exist without bearing any relation to reality. These four 'ways of existence' cannot all be discussed here in detail (for closer examination, see Seppänen, 2001b: 66-74); however, the fourth can be focused on when inspecting the Hervanta pictures. In this context, the picture in a way creates its own reality, which is a thought that approaches Stuart Hall's (1997b) idea of representation as a construction, as summarised above. Baudrillard's (1988) suggestion of a picture no longer bearing any relation to reality actually entails that reality is merely simulation and the picture is more 'true' or 'real' than reality. Radicalised to the bottom, this suggestion forms a basis for arguing that the nature of nature and wildlife photographs is more real than material or physical nature. In a way, nature is emptied into its picture, which is experienced by people who consume advertisements and television nature documentaries. Even if Baudrillard's idea were not completely accepted, some of it can be regarded as accurate. People often experience nature as simulation, pictures and different kinds of representations or displays; therefore, the Hervanta pictures need to be explored in light of the above-mentioned context as well as the politics of representation realisedn this context. The pictures can be set as a part of simulated nature; in other words, the pictures become nature itself. Typical of this kind of imagery is the abstraction of the representations; i.e., they do not bear any visible relation to those social and financial processes that actually shape and define nature. Simultaneously, simulated nature can, in the form of a symbol or combination of symbols, be combined with another symbol, thus creating a combination that appears arbitrary. Representations of nature can be applied in any context desired, ranging from the Two Pictures of My Town project to car advertisements.

\section{Teisko: Admiring a Countryside Landscape}

The two pictures representing the town district of Teisko were chosen by an active citizen who had prior to this participated in the operation of the Manse Square web community. The contact person tried to inspire other residents of the area to take part in choosing the pair of photographs, but the final decision was left to her. However, dur- 
ing the process of selection, it was necessary to take into account the fact that the pictures would represent the residents of the area and, thus, the interests of more than just one person alone. How should the town district be presented so that the representation would be approved by, at the least, the majority of the residents of the area? Therefore, in this case selecting the pictures can also be regarded as a part of the politics of representation; in other words, defining the line between the visible and the invisible.

The first picture depicting the town district of Teisko portrays one of the icons of Finnish countryside imagery; in the words of the photograph's caption: "Platform for milk churns - a part of Finnish countryside culture." The other picture shows the Aunessilta bridge across Paarlahti bay, the bridge being possibly the best-known sight of Teisko. The caption of the second picture informs the viewer: "'Connecting people' since 1899. Aunessilta bridge in Paarlahti."

As opposed to the Hervanta photographs, these pictures do not illustrate anonymous locations in the bosom of nature. One of the unique sights of the Velaatta area in Teisko is a "milk churn-platform museum", and several postcards depicting Teisko portray the Aunessilta bridge. Moreover, the well-known advertisement slogan 'Connecting people', introduced by the Finnish mobile communication giant Nokia, creates an ironic secondary meaning, simultaneously drawing a parallel between the present era of networking and the past, when 'connecting people' meant first and foremost building roads and bridges.

Whereas the Hervanta photographs are linked with the visual orders typical of the nature and wildlife photograph, the Teisko pictures open a view into the romantic countryside. The representation follows the imageries of travel brochures in crystallising different meanings of a particular area into a few central, well-known sceneries. As examples of typical Finnish metonyms, the Näsinneula tower of Tampere and Esplanade park in Helsinki can be mentioned. Metonyms such as these present the central imagery of the location, i.e., its visual order, to the gaze of the tourist and his camera. According to John Urry (1990: 1), the gaze of the tourist is culturally defined; in other words, only certain specified locations will be photographed, and in some cases tourists are even instructed to take a photograph of a specified spot.

People are tourists in their leisure time, i.e., when free from the obligations of their work. According to Urry (1990: 3), the tourist's gaze is directed at those places that differ from his or her everyday life experiences, and are therefore anticipated to have a powerful impact on their viewer. Expectations concerning different kinds of places of visit are built on the public imageries presented in television, periodicals and travel brochures, among other media. People fantasise and daydream of the locations before actually embarking on the journey. Having arrived at the location they will then visit the places that have become a part of their fantasies, and finally they will buy a postcard or take a photograph of the exact spot that has become familiar through a picture printed in a travel brochure. As Urry points out (Urry, 1990: 3), this enables repeating the gaze and fixing it on the target over and over again.

Thus, the visual orders of the Teisko pictures reflect the tourist gaze, which is fixed on the exceptional sights of the area. This is essentially a case of posing and making an appearance. If politics of representation is regarded as including active choices during the selection process, the Teisko photographs realise these politics, which rely on choices that are relatively safe and generally recognised. The Teisko pictures portray not so much the way Teisko looks but the way Teisko is usually represented pictorially. Thus, the primary target of reference is not so much the actual and real Teisko landscape, but the Teisko of tourist pictures, spreading itself onto postcards as well. Moreover, a 
few of the other pictures of the Two Pictures of My Town project also aim at presenting the area to the tourist gaze in terms of a similar logic; for example, the Pispala pictures can be mentioned. Naturally, the tourist gaze was in a way enforced by the fact that the pictures would be shown to an international audience via the NaviTam application, and those making the picture selections were aware of this fact.

In conclusion, the politics of representation perceivable in the Teisko pictures follow the visual orders of the established tourist imagery. These focus on a few exceptional locations that are considered worth seeing and experiencing, in other words regarded as the main tourist attractions of the area. It can be assumed that most residents of the district will approve of such representations as metonyms of their own region; after all, they are tried and tested, and they do not involve negative values or images.

\section{Järvensivu: Life between Concrete and Wood}

The photographs depicting the town district of Järvensivu were taken by the contact person of the area, who was also responsible for selecting the pair of pictures to be presented on the Internet. The contact person had brought up the Two Pictures of My Town project in a meeting of the local resident society, and the idea of portraying changes in the history of the area was supported as a theme for the pair of pictures. However, the contact person made the final decisions in selecting the pictures.

The dynamics of the pair of pictures rely upon displaying the old and the new sides of Järvensivu. One of the photographs depicts an old residential house, the caption attached to it explaining: "Järvensivu in the beginning of the $20^{\text {th }}$ century". The other picture portrays a colourless concrete building: "Järvensivu in the beginning of the 1970s". It is not difficult to perceive the message conveyed by the pair of pictures; they clearly point to the changes in the picture of 'our town'.

This pair of pictures is the only one of the Two Pictures of My Town project clearly attempting to demonstrate the changes during the times in the town district. Between the lines, one can read a statement in favour of preserving the old image of the town district. This pair of pictures opens a connection to the general social struggles in preserving or changing any scenery, these struggles often being instigated by town plan proposals concerning public space. The residents' view may differ to a great extent from those of the municipality officials and builders, and, therefore, quite often these struggles turn into citizen activism, manifested in gathering petitions, squatting and in public debates.

Perhaps the most recent example of such citizen activism in the town of Tampere is the struggle for and against building a bridge between Koskenniska and Mältinranta; pictorial representations have played a significant part in this particular struggle (see, e.g., Ridell, 2001). In 1997, the Mältinranta Movement was established by citizens of Tampere opposed to building the bridge. These active citizens gathered a petition with 10,000 signatures to support a citizen motion, which was initiated in April 1999 with the aim of having the bridge revoked from the town plan. According to those opposing the building project, the bridge, designed to be built on the upper course of Koskenniska rapids, would spoil the priceless cultural scenery; on the other hand, those in favour of building the bridge justify the project by, for example, traffic organisations. Essential in the pictorial representations and the corresponding visual orders is the fact that both those in favour of (i.e., the town of Tampere) and those against the project have produced their own pictorial representations of the bridge. Those opposed to the project depict the bridge substantially heavier in comparison to the pictures ordered by the town of Tampere from a private planning agency. Both pictorial representations rely on a chronological sequence, i.e. a setting of 'before and after'. 
In this case, those against the bridge made different kinds of choices in terms of politics of representation than those in favour of the project. The opponents produced scenery that differs in its visual order and, therefore, in meanings, from the scenery depicted by the 'official' pictures of the bridge commissioned by the town of Tampere. As it is, no absolutely 'right' view of the bridge exists. Depicted from below, the bridge appears to cover the whole sky, whereas when viewed from an aeroplane, the bridge can hardly be detected amid the scenery of rapids. Since there is no 'right' visual order to describe the bridge, it follows that each representation of it is a construction, i.e. a result of political and financial interests.

When depicting change, the 'before and after' setting is one of the most frequently applied pictorial conventions. Both the Koskenniska-Mältinranta bridge briefly discussed above and the pair of pictures describing the Järvensivu town district apply this setting, although the Järvensivu pictures merely insinuate, delicately and politically less explicitly, their purpose. This pair of pictures draws a relation between the past and the present quietly and immodestly, not bringing forth the culture, history, or mechanisms of local decision-making that have led to the changes in the area. This would not even have been possible, owing to the format of representation applied in the presently discussed project.

The politics of representation in the Järvensivu pictures are derived from the thought that pictorial representations allow commenting on, and even criticising, the changes that have occurred in a residential area. The pair of pictures applies this thought by building two situations, i.e. 'before' and 'after', in order to bring out the change in history. Simultaneously, a critical tension is created between the new and the old; in a blunt simplification: old wooden buildings are beautiful, whereas concrete buildings are ugly. Thus viewed, as a representation this pair of pictures is attached to the broader-scale values and discussion concerning residential surroundings and landscape.

\section{Constructing Local Identities}

Stuart Hall (1992b: 292-293) writes about national cultures as follows: "National cultures are composed not only of cultural institutions, but of symbols and representations. A national culture is a discourse - a way of constructing meanings which influences and organizes both our actions and our conception of ourselves. [...] National cultures construct identities by producing meanings about the 'nation' with which we can identify; these are contained in the stories which are told about it, memories which connect its present with its past, and images which are constructed of it."

By altering variables, Hall's thoughts on national culture apply to the case of local identity. For example, the Teisko pair of pictures not merely conveys a realistic image of the town district of Teisko, but also exists as a tool for building the local identity: this is how we wish to be seen by the outsiders' gaze; this is a part of being a resident of Teisko, and with this we can identify ourselves. The conclusions expressed here were observable in discussions with the contact persons of different town districts: one described the selection process as a negotiation, which meant not acting merely based on one's own preferences but also taking other residents' opinions into account.

Thus, it has been shown that identity formation can be characterised as active, interactive and operating in relation to the outer world. This brings us to the core of the politics of representation. Although only a few town districts selected their representative pictures in residents' meetings, it was observable that a type of community norm directed the choosing process even in the cases of town districts in which the residents 
did not collaborate during the selection. A kind of quiet negotiation was carried out in these cases, debating which representations could be suitable. Not just any kinds of pictures could have been displayed; in other words, not just any kinds of visual orders could have been included as a part of the identification process of the town district. The pictures selected for the purposes of the Two Pictures of My Town project are similar in that they have all been produced as representations for the (tourist's) gaze and, simultaneously, for one's own community. However, the building processes concerning the identities of different town districts vary rather significantly in terms of their content.

As mentioned above, the Hervanta sixth-form college is attended by pupils living outside the suburb of Hervanta, and the producers of the pair of pictures that won the school's photograph contest do not reside in Hervanta themselves. Moreover, the situation of photography is different from the other town district communities: the Hervanta pictures were produced not only for the outsider's gaze, but also for that of fellow pupils and the teacher. The pair of pictures needs to be viewed as a part of schoolwork and the social networks of the class as well as the identifications connected to them. Naturally, these processes are very difficult to detect from the picture itself; in order to explicate these, the social field of the picture production would need to be surveyed and interpreted. Nevertheless, the visual orders of the Hervanta pictures are related to the general, even anonymous, visual orders of the nature and wildlife photograph. Although nature is part of being a resident of Hervanta, it is not an area of meaning connected particularly or solely to Hervanta. Nature photography is one of the central interests of leisure time photographers, and nature itself, as a free-time hobby in one form or the other, offers a positive surface of identification. Therefore, it is a natural choice in terms of the world of meanings attached to Hervanta as well. Moreover, a sense of irony, targeted at the assignment itself, can be detected in the pair of pictures selected by the sixth-form class; thus, in this context, the pair of pictures is specific in the identity formation it conveys of the dynamics concerning the class and the whole school, i.e. the picture producers' identities as sixth-form pupils. If the pictures are viewed as an ironic comment on the assignment, they can be regarded as a manifestation of a counter-culture, opposing the official school culture. In this case it follows that the 'imaginary community', which affected the choice of the pictures, is built on counter-cultural social dynamics - a fact that defines in its part the politics of representation crystallised in the pictures.

The case of the Hervanta pictures has shown that the relation to the location portrayed can, on the one hand, be regarded as potentially anonymous. On the other hand, the Teisko photographs portray central symbols of the town district, these being known and shared by everyone. One of the main functions of photography can be said to be that of strengthening the family identity; family albums are filled with pictures of the family portrayed together (cf., e.g., Slater, 1995). This principle can be applied to a social unit larger than the family; in the context of the Two Pictures of My Town project, this can be seen in the pictures of the town districts of Käpylä and Viinikka. The Viinikka photographs depict the views of two generations, thus trying to prove the town district to be an excellent area for people of all ages. The flock of children shown in the Käpylä pictures can be seen as a literal metaphor for coexisting as one big family. Both pairs of pictures aim at convincing those residing in the area as well as the imagined outsiderviewer of the nature of the area. Thus, the good features of the district are focused on in order to enforce the inner identity as well as that shown to outsiders. Therefore, the assumed audience is both residents of the area as well as occasional visitors to the web site. The same applies to the Teisko pictures, although they do not portray 'the family', but frame places of pride shared by the whole region, which therefore can relatively 
unanimously be selected to be presented to the gaze of others, i.e. 'tourists' in the broadest sense of the word.

The Järvensivu pictures, particularly with regard to the community identity built by the pictures, are more problematic in terms of their visual order and politics of representation than the safe decisions made in the selection of the Teisko pictures. It may well be that not all of the Järvensivu residents share the view of 'old and new' as opposing each other in the way shown in the pair of pictures chosen to represent the town district. For instance, the perspective of people living in concrete buildings remains to be speculated. In other words, this kind of emphasis on the history and development of the area differs from a shared and generally approved picture, such as those of 'the tourist picture' and 'the untouched nature picture'. The visual orders in the Järvensivu pictures may even convey a conflict in substantial values, which forms a notably less united basis for identification than the politics of representation realising in the Teisko and Hervanta pictures. On the other hand, the Järvensivu pictures provide alternative space of identification for those who do not accept prevailing visual orders of their neighbourhood.

The Two Pictures of My Town project has first and foremost shown that pictorial representations can be applied in building a family-like sense of identity by choosing visual orders that are shared and therefore safe in meaning. Simultaneously, this conclusion raises the question of what kinds of politics of representation and identity formation would be based on differences of opinion, conflicts and tarnishing one's own reputation by also presenting the gaze of others with the less attractive features of one's own residential area. Brought to a more general level, the question turns into a discussion of which kinds of visual orders are desirable and which can be regarded as undesirable in terms of building the identity of a certain district. Whose gaze defines the conditions according to which these orders are produced?

\section{Literature}

Barthes, R. (1987a) The Photographic Message. In Barthes, R.: Image, Music, Text. Essays selected and translated by Stephen Heath. London: Fontana, pp. 15-31.

Barthes, R. (1987b) Rhetoric of the Image. In Barthes, R.: Image, Music, Text. Essays selected and translated by Stephen Heath. London: Fontana, pp. 32-51.

Baudrillard, J. (1988) Selected Writings. Edited and Introduced by M. Poster. Stanford: Stanford University Press.

Bourdieu, P., Boltanski, L., Castel, R., Chamboredon, J-C. \& Schnapper, D. (1990) Photography. A Middlebrow Art. Translated by Shaun Whiteside. Cambridge: Polity Press.

Braden, S. (1983) Committing Photography. London: Pluto Press.

Burnett, R. (1995) Cultures of Vision. Images, Media and the Imaginary. Bloomington: Indiana University Press.

Foucault, M. (1986) Power/Knowledge. Selected interviews and other writings 1972-1977. Ed. by Colin Gordon. Suffolk: The Harvester Press.

Hall, S. (1992a) Identity, ten8, 2(3)1992, pp. 24-31.

Hall, S. (1992b) The Question of Cultural Identity. In Hall, S., Held, D. \& McGrew, T. (eds.) Modernity and Its Futures. London: Politi Press \& Open University, pp. 273-326.

Hall, S. (1997a) The Spectacle of the 'Other'. In Hall, S. (ed.) Representation. Cultural Representations and Signifying Practices. London: Sage \& Open University, pp. 223-290.

Hall, S. (1997b) The Work of Representation. In Hall, S. (ed.) Representation. Cultural Representations and Signifying Practices. London: Sage \& Open University, pp. 13-74.

Heinonen, A., Mäkinen, M., Ridell, S., Martikainen, A., Halttu, M. \& Sirkkunen, E. (2000) Locality in the Global Net. The Internet as a space of citizen communication and local publicness. (June/2003) < http://mansetori.uta.fi/report/default.htm $>$.

Holland, P. (1997) 'Sweet It Is to Scan... Personal Photographs and Popular Photography.' In Wells, L. (ed.) Photography - a Critical Introduction. London: Routledge, pp. 103-150. 
Karttunen, S. (1997) 'Pierre Bourdieu valokuvan kimpussa. Mikä on Art Moyenin anti tämän päivän tutkimukselle?’ [How to read Pierre Bourdieu's Un Art Moyen.] Tiedotustutkimus 20(3)1997, pp. 1122.

Karvonen, E. (1991) 'Representaation politiikka ja sukupuolen tuotanto.' [The Politics of Representation and the Making of Gender] Sosiologia vol 28(1)1991, pp. 25-32.

Koskinen, I., Kurvinen, E., Lehtonen, T-K. (2001) Mobiili kuva. [Mobile Picture] Helsinki: Edita/IT Press. Lacan, J. (1977) Écrits. A Selection. London: Tavistock Publications. (Transl. by Alan Sheridan.)

Ridell, S. (2001) 'Manse Forum - a Local Experiment with Web-Mediated Civic Publicness.' In Heinonen, A., Mäkinen, M., Ridell S., Martikainen, A., Halttu, M. \& Sirkkunen, E.: Locality in the Global Net. The Internet as a Space of Citizen Communication and Local Publicness. Tampere: Journalism Research and Development Centre, University of Tampere.

Seppänen, J. (1993) 'Places', in Nuutinen, P. \& Seppänen, J.: Paikkoja/Places. Helsinki: Musta Taide, pp. VIII-XI.

Seppänen, J. (1997) Miten lähestyä valokuvaa. Kolme teoreettista mallia valokuvan tutkimiseksi. [How to Study Photograph. Three theoretical models.] Sosiologia 34(1)1997, pp. 53-63.

Seppänen, J. (2001a) Young People, Researchers and Benetton. Contest Interpretations of a Benetton Advertisement Picture. Nordicom Review 22(1)2001, pp. 85-96.

Seppänen, J. (2001b) Katseen voima. Kohti visuaalista lukutaitoa. [The Power of Gaze. Towards Visual Literacy.] Tampere: Vastapaino.

Seppänen, J. (2001c) Valokuvaa ei ole. [The Photograph Does Not Exists] Helsinki: Musta Taide \& Suomen valokuvataiteen museo.

Silverman, K. (1996) The Threshold of the Visible World. New York \& London: Routledge.

Slater, D. (1995) Domestic Photography and Digital Culture. In Lister, M. (ed.): The Photographic Image in Digital Culture, pp. 129-146. London \& New York: Routledge.

Spence, J. (1995) Cultural Sniping. The Art of Transgression. London \& New York: Routledge.

Tagg, J. (1988) The Burden of Representation. Essays on Photographies and Histories. London: Macmillan.

Tarasti, E. (1990) 'Maiseman semiotiikasta.' [On the Semiotics of Landscape.] In E. Tarasti: Johdatusta semiotiikkaan. Esseitä taiteen ja kulttuurin merkitysjärjestelmistä. [Introduction to Semiotics. Essays on Meaning Systems of Art and Culture.] Helsinki: Gaudeamus, pp 68-80.

Toiskallio, K. (1997) Yksin yhdessä - automainoksessa. Sanan ja kuvan yhteispeli mainoksen sosiaalisella näyttämöllä. [Words and Pictures on the Social Scene of Car Advertisements.] Tiedotustutkimus 20(3)1997, pp. 74-85.

Urry, J. (1990) The Tourist Gaze. Leisure and Travel in Contemporary Societies. London: Sage.

Wells, L.(ed.) (1997) Photography - A Critical Introduction. London: Routledge. 